\title{
Variability in quality of white and green beans during in-pack sterilization
}

\author{
I.M.L.B. Ávila ${ }^{\text {a }}$, R.C. Martins ${ }^{\text {b }}$, P. Ho ${ }^{\text {c }}$, M. Hendrickx ${ }^{\text {d }}$, C.L.M. Silva ${ }^{\text {b,* }}$ \\ ${ }^{a}$ Departamento de Química, Universidade de Aveiro, Campus de Santiago, 3810-083 Aveiro, Portugal \\ ${ }^{\mathrm{b}}$ Universidade Católica Portuguesa, Escola Superior de Biotecnologia Rua Dr. António Bernardino de Almeida, 4200-072 Porto, Portugal \\ ${ }^{\mathrm{c}}$ Departamento das Ciências da Engenharia e Tecnologia, Escola Superior de Tecnologia e Gestão, Instituto Politécnico de Viana do Castelo, \\ Apartado 574, 4901-908 Viana do Castelo, Portugal \\ ${ }^{\mathrm{d}}$ Laboratory of Food Technology, Katholieke Universiteit Leuven, Kasteelpark Arenberg 22, B-3001 Leuven (Heverlee), Belgium
}

Keywords: Sterilization; Pre-packaged foods; Quality retention; Variability; Green beans; White beans

\begin{abstract}
Non-uniformity in process quality was investigated during in-pack thermal sterilization of food products. This was accomplished through the combined application of the Monte Carlo procedure and a reliable mathematical method for process evaluation. Despite the large coefficients of variation found, the optimum quality process could be designed. The influence of the statistical variability of heating rate index on the retention of green beans' color was studied and an optimum temperature range was found between 125 and $135^{\circ} \mathrm{C}$. The variability in hardness of sterilized white beans, resulting from uncertainties of the combined effect of heating rate index and initial hardness of beans, was also evaluated by simulation. In this case, an optimum global temperature range between 120 and $135^{\circ} \mathrm{C}$ was found, independently of the rotation, $F_{0}$ value and surface heat transfer coefficient assumed.
\end{abstract}

\section{Introduction}

Adequate evaluation of a process technology's impact on food safety and quality is essential for its viability and market acceptance (Smout, 1999). In the field of food sterilization, the minimum required thermal process should be designed to assure the desired microbial safety, and consequently produce minimal effects on product quality (Banga, Balsa-Canto, Moles, \& Alonso, 2003; Lund, 1975). Both heating costs and product quality losses increase as the process time is lengthened (Banga et al., 2003; Clealand \& Robertson, 1985).

\footnotetext{
* Corresponding author. Tel.: +351 2255 80058; fax: +351 2250 90351.

E-mail address: clsilva@esb.ucp.pt (C.L.M. Silva).
}

Variations during thermal processing can arise naturally, even when operating the retort in a standard controlled manner. A sterilization process can be affected by a large number of factors, which are not known accurately (stochastic factors), and are related to: (i) variability in heat transferred to the food product (e.g. retort temperature, rotational speed, surface heat transfer coefficient), (ii) variability in product and container characteristics (e.g. composition of products, product homogeneity, product thermophysical properties, such as thermal diffusivity, initial product temperature, headspace volume, can fill weight), and (iii) variability in parameters of microbial or quality kinetics $\left(k, E_{\mathrm{a}}, D\right.$, $z$, initial spore load, initial quality). Uncertainty in any of these factors will result in an uncertainty in the delivered lethality, with consequent effects on the quality level (Clealand \& Robertson, 1985; Hicks, 1961; Nicolai, 


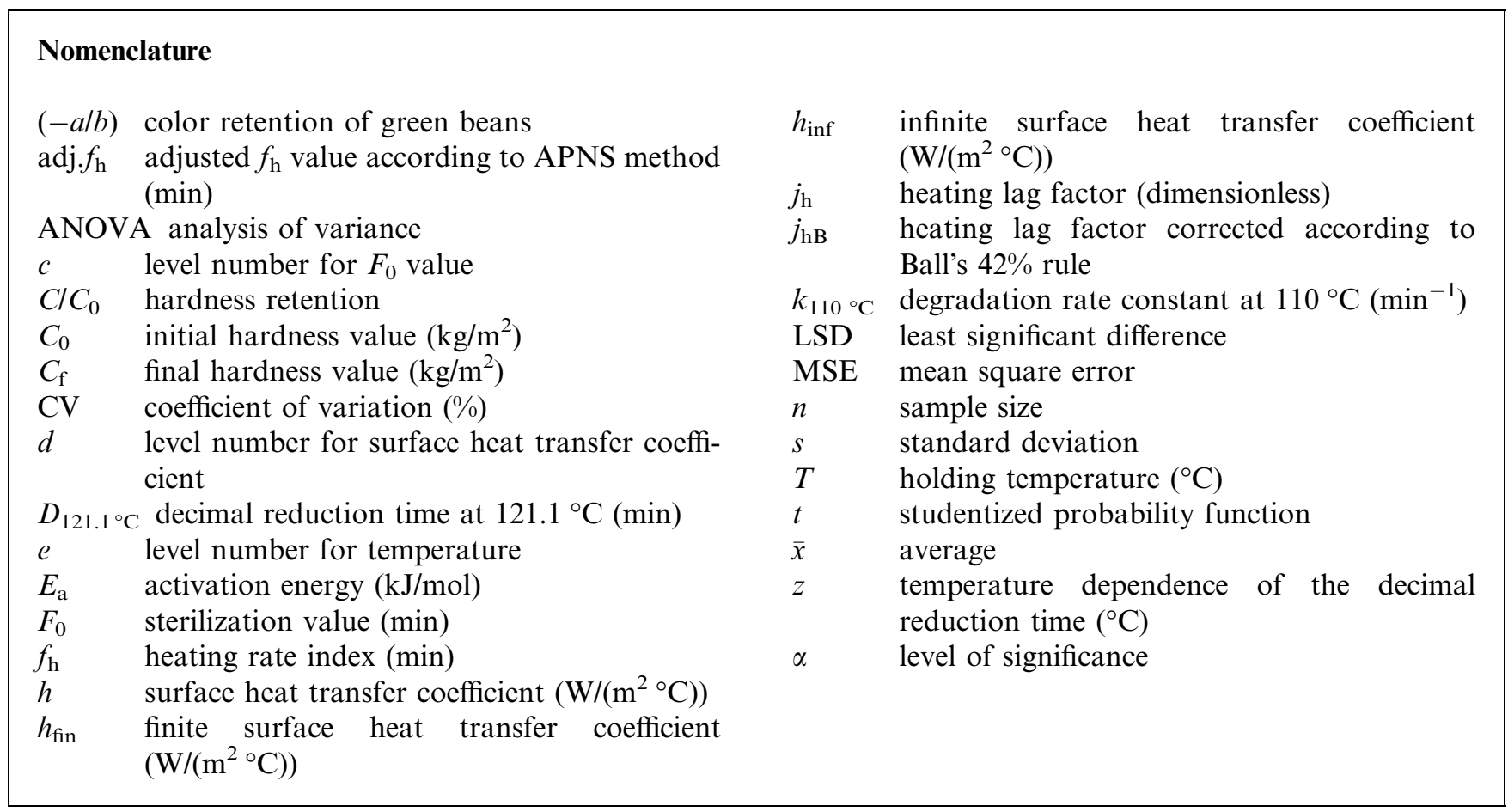

1994; Smout, 1999, Smout, Ávila, Van Loey, Hendrickx, \& Silva, 2000a, 2000b; Varga, 1998).

Consequently, commercially sterilized food products are over processed to include additional safety margins that account for inherent variability in sterilization. This inherent variability cannot be avoided, however it is possible to estimate it, in order to develop adequate process assessment (Hicks, 1961; Nicolai, 1994; Varga, 1998). Hicks (1961) was one of the first authors who published work about the nature of uncertainties in canning processes. He discussed the uncertainties in lethality resulting from uncertainties in both heat penetration and bacteriological data. Powers, Pratt, Carmon, Somaatmadja, and Fortson (1962) reported coefficients of variation $(\mathrm{CV})$ for the $F_{0}$ values of six products studied ranging from $16.3 \%$ to $57.4 \%$, where the variance in heat penetration parameters was considered. Subsequently, many other authors (Hayakawa, De Massaguer, \& Trout, 1988; Herndon, 1971; Jones, Pflug, \& Blanchett, 1980; Lenz \& Lund, 1977; Lund, 1978; Patino \& Heil, 1985; Robertson \& Miller, 1984; Smout et al., 2000a, 2000b) have studied the influence of variability of various parameters on process lethality.

Variations in quality retention from container to container, in a retort batch, can be so large that it might be difficult, or even impossible, to design an optimal process (Smout, Banadda, Van Loey, \& Hendrickx, 2003). On this subject, only Smout et al. (2003) reported the non-uniformity in surface quality (color of green peas) during thermal processing. No other research studies on the effect of uncertainties on quality retention of foods have been reported yet.
Therefore, in this framework, the objective of this study was to investigate non-uniformity in quality retention during in-pack thermal processing of foods. A feasible statistical approach is proposed to assess process optimization design. Two case studies are presented: the influence of the heating rate index $\left(f_{\mathrm{h}}\right)$ variability on the retention of green beans' color, and the influence of the combined effect of heat penetration rate $\left(f_{\mathrm{h}}\right)$ and initial hardness variability on white beans final hardness retention.

\section{Materials and methods}

\section{White beans}

Dried white beans were obtained from a canning company and stored dry at $15^{\circ} \mathrm{C}$. Before processing, the white beans were soaked in distilled water at $15^{\circ} \mathrm{C}$ for at least $16 \mathrm{~h}$. The heat penetration trials were carried out in a pilot water cascading retort (Barriquand Steriflow retort. Paris, France). The beans were placed in $370 \mathrm{~mL}$ glass jars $(84 \mathrm{~mm}$ height, $75 \mathrm{~mm}$ diameter, and $2.6 \mathrm{~mm}$ thickness) filled with distilled water and the retort operated in both static and end-over-end rotary modes. The heat penetration parameters, heating rate index $\left(f_{\mathrm{h}}\right.$ value $)$, lag factor $\left(j_{\mathrm{h}}\right.$ value $)$, and corrected lag factor according to Ball's $42 \%$ rule ( $j_{\mathrm{hB}}$ value) were calculated using the Ball's (1923) formula method. Adjusted $f_{\mathrm{h}}$ and $j_{\mathrm{h}}$ values were estimated using a semiempirical approach, the Apparent Position Numerical 
Solution (APNS) method (Noronha, Hendrickx, Van Loey, \& Tobback, 1995).

The kinetics of thermal softening of white beans were determined using cans of $71 \mathrm{~mm}$ diameter and $27 \mathrm{~mm}$ height, heated in a thermostated oil bath. The hardness of $100 \mathrm{~g}$ of heat-treated white beans were measured with an industrial Tenderometer unit (FMC, model 4011). The thermal softening kinetics were analyzed using a fractional conversion model (first order irreversible reaction) (Levenspiel, 1999).

The procedures applied, the parameters assumed and results obtained are described in detail in Ávila, Smout, Silva, and Hendrickx (1999).

Table 1 presents the values used to generate 300 random (normally distributed) adjusted $f_{\mathrm{h}}$ values and initial hardness $\left(C_{0}\right)$ values, using Monte Carlo simulations.

\section{Green beans}

Broken green beans, produced in Belgium, were purchased frozen in a local supermarket and were all provided from the same lot number. The green beans were kept frozen until used in the experiments. Immediately before each experiment, the green beans were defrosted under warm tap water $\left(20^{\circ} \mathrm{C}\right)$ for $5 \mathrm{~min}$, and then drained off during 2 min. Green beans' heat penetration rate was determined by similar procedures applied to white beans case study. In this case only the retort static mode of operation was used (Ávila, 2001; Ávila et al., 1999).

Values used in simulations are presented in Table 1.

\section{Approach to assess process quality optimization}

The approach used in this work is schematically illustrated in Fig. 1 for the white beans case study. Smout et al. (2000b), also using the Monte Carlo technique, developed a similar approach to evaluate the non-uniformity in lethality delivered to the food product, resulting from

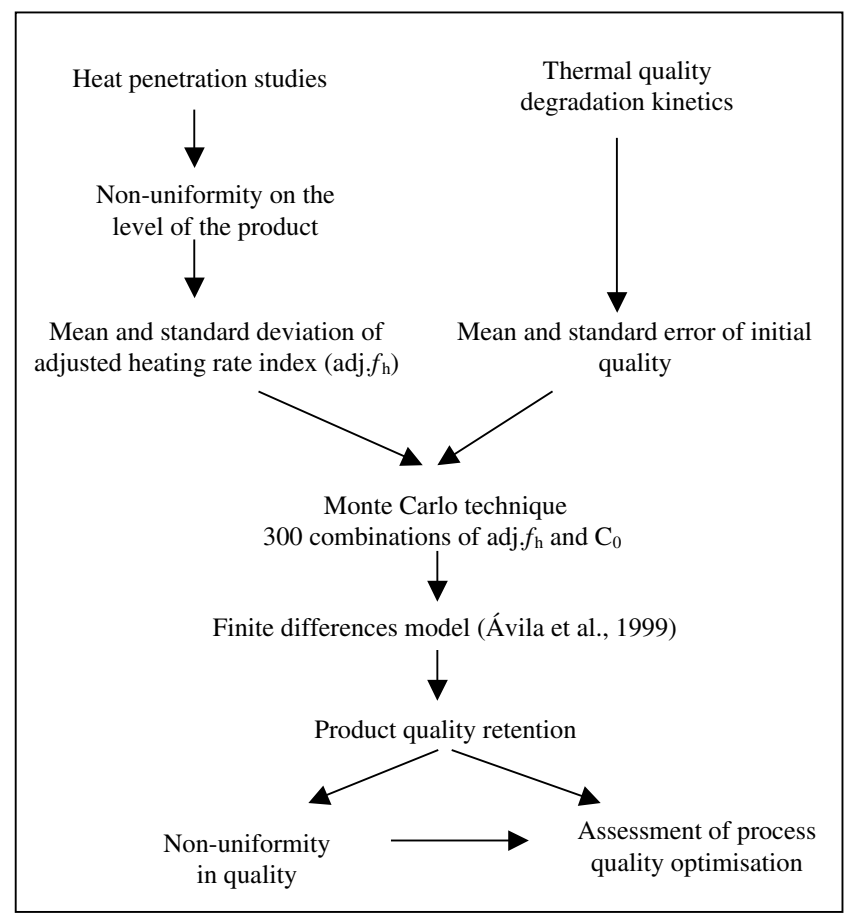

Fig. 1. Schematic representation of the approach used in the case study with white beans.

the combined effect of the variability of product heating characteristics and retort temperature. In the present study, the non-uniformity in quality (texture) retention of sterilized white beans was investigated by combining the non-uniformity on the level of the product (heat penetration data) with uncertainties on the initial hardness $\left(C_{0}\right)$ of the beans. The mean and standard deviation of the adjusted heating rate index $\left(\operatorname{adj} . f_{\mathrm{h}}\right)$ were combined with the mean and standard error of the initial quality, through Monte Carlo simulations. Three hundred random combinations of adjusted $f_{\mathrm{h}}$ values and $C_{0}$ were generated, assuming normal distribution of both factors. The number of simulations (300) was chosen to assure

Table 1

Values used in the simulations for white and green beans case studies (Ávila, 2001; Ávila et al., 1999)

\begin{tabular}{|c|c|c|}
\hline & White beans & Green beans \\
\hline Kinetic parameters & $\begin{array}{l}E_{\mathrm{a}}=120 \mathrm{~kJ} / \mathrm{mol} \\
k_{110^{\circ} \mathrm{C}}=0.066 \mathrm{~min}^{-1} \\
C_{\mathrm{f}}=26.0 \mathrm{~kg} / \mathrm{m}^{2} \\
\bar{x}_{C_{0}}=211.8 \mathrm{~kg} / \mathrm{m}^{2} \\
s_{C_{0}}=7.1 E 3 \mathrm{~kg} / \mathrm{m}^{2}\end{array}$ & $\begin{array}{l}z \text {-value }=38.9{ }^{\circ} \mathrm{C} \\
D_{121.1{ }^{\circ} \mathrm{C}}=21 \mathrm{~min} \\
\text { Hayakawa and Timbers }(1977)\end{array}$ \\
\hline$F_{0}$ values & $\begin{array}{l}3 \mathrm{~min} \\
5 \mathrm{~min}\end{array}$ & $\begin{array}{l}3 \mathrm{~min} \\
5 \mathrm{~min}\end{array}$ \\
\hline Heat penetration data (adjusted $f_{\mathrm{h}}$ value) & $\begin{array}{l}0 \mathrm{rpm}: \bar{x}_{\text {adj. } f_{\mathrm{h}}}=9.06 \mathrm{~min}, s_{\text {adj. } . f_{\mathrm{h}}}=0.75 \mathrm{~min} \\
10 \mathrm{rpm}: \bar{x}_{\text {adj. } . f_{\mathrm{h}}}=6.51 \mathrm{~min}, s_{\text {adj. } . f_{\mathrm{h}}}=0.69 \mathrm{~min}\end{array}$ & $\begin{array}{l}\bar{x}_{\text {adj. } f_{\mathrm{h}}}=7.87 \mathrm{~min} \\
s_{\mathrm{adj} . f_{\mathrm{h}}}=0.37 \mathrm{~min}\end{array}$ \\
\hline Surface heat transfer coefficient $(h)$ & $\begin{array}{l}h_{\mathrm{fin}}=408 \mathrm{~W} /\left(\mathrm{m}^{2} \mathrm{~K}\right) \\
h_{\mathrm{inf}}\end{array}$ & $\begin{array}{l}h_{\mathrm{fin}}=408 \mathrm{~W} /\left(\mathrm{m}^{2} \mathrm{~K}\right) \\
h_{\mathrm{inf}}\end{array}$ \\
\hline Heating medium holding temperature range & $100-160^{\circ} \mathrm{C}$ & $100-160^{\circ} \mathrm{C}$ \\
\hline
\end{tabular}


results with a low error $(\varepsilon<0.05)$ (Hahn \& Shapiro, 1994).

For each run generated, volume average quality retention was calculated using a finite differences model (Ávila et al., 1999) for different holding temperatures $\left(100-160{ }^{\circ} \mathrm{C}\right)$, considering finite $\left(408 \mathrm{~W} /\left(\mathrm{m}^{2} \mathrm{~K}\right)\right)$ and infinite surface heat transfer coefficient, for $F_{0}$ values of 3 and $5 \mathrm{~min}$ at static mode or $10 \mathrm{rpm}$ retort processes (Ávila et al., 1999). Industrial retorts can only operate at a maximum of $135^{\circ} \mathrm{C}$, however, it was necessary to perform simulations until $160^{\circ} \mathrm{C}$ in order to better visualize the optimum quality retention.

In the case of green beans, the finite differences model calculates color retention $(-a / b)$ of green beans as a function of process temperature. In this case, a more simplified approach was utilized, since the kinetic parameters for color degradation were taken from the literature (first order model: $z$-value $=38.9^{\circ} \mathrm{C}$, $D_{\text {tref }}=121.1^{\circ} \mathrm{C}=21 \mathrm{~min}$ : Hayakawa \& Timbers, 1977) and, therefore, no variability at this level was taken into account.

\section{Statistical analysis}

A three-factor fixed effects ( $F_{0}$ value, $h$ value and temperature) Analysis of Variance (ANOVA) was performed for each case study, using Statistica (2001), at a $5 \%$ level of significance. Multiple pairwise comparisons of treatment means were performed, using a $95 \%$ confidence interval based on least significant difference (LSD). The LSD was calculated using the following formula (Neter, Kutner, Nachtsheim, \& Wasserman, 1996):

$\mathrm{LSD}=t_{[(1-\alpha / 2),(c d e(n-1))]} \times \sqrt{\frac{\mathrm{MSE}}{n}}$

where $t$ is the studentized probability function; $\alpha$ the level of significance (which is 0.05 ); $c$ the level number for $F_{0}$ value (which is 2); $d$ the level number for surface heat transfer coefficient (which is 2), $e$ the level number for temperature (which is 13); $n$ is the sample size (which is 300) and MSE is the mean square error.

\section{Results and discussion}

\section{White beans}

The non-uniformity in hardness of white beans was simulated taking into consideration the combined variability in the heating rate index and initial texture (Table 1). Analyzing Table 2, for the static retort mode of operation and considering the experimental range of retort temperatures $\left(100-135^{\circ} \mathrm{C}\right)$, the coefficients of variation $(\mathrm{CV}=s / \bar{x} \times 100)$ for simulated hardness retention, of the combined effect, range from $1.7 \%$ to $14.6 \%$. This means that the simulated uncertainties in the heating rate index and initial hardness have large effects on the final average texture variability, at high temperatures. It can be observed from Table 2 that $\mathrm{CV}$ values increase with increasing temperature. At high temperatures, processing times are considerably smaller and slight changes in heat transferred to the product can cause large variations in the final quality retention (e.g. at $T=135^{\circ} \mathrm{C}$, for $f_{\mathrm{h}}=11.17 \mathrm{~min}, C / C_{0}=22.1 \%$; while for $f_{\mathrm{h}}=7.79 \mathrm{~min}$, $C / C_{0}=16 \%$ ). On the other hand, at low temperatures of $100-115^{\circ} \mathrm{C}$ the processing times are so large, that the temperature gradient inside the product becomes homogeneous and, therefore, the variations in terms of final average quality retention become very small.

Comparing both finite and infinite $h$ values, the coefficients of variation are lower for finite $h$ values (Table 2). Assuming an infinite $h$ value, means to consider no surface resistance to heat transfer (e.g. product packed in a metallic container and steam as heating medium). Consequently, the sterilization value is achieved faster than for a finite $h$. In addition, a larger temperature gradient can be found inside the container, because the product surface becomes subjected to higher tempera-

Table 2

Coefficients of variation $(\mathrm{CV})$ for simulated hardness retention of white beans at different holding temperatures, $F_{0}$ values of 3 and 5 min, finite and infinite surface heat transfer coefficients $(h)$ and static retort mode of operation

\begin{tabular}{llccc}
\hline$T\left({ }^{\circ} \mathrm{C}\right)$ & $\mathrm{CV}(\%)\left(h_{\text {inf }}, F_{0}=3 \mathrm{~min}\right)$ & $\mathrm{CV}(\%)\left(h_{\text {fin }}, F_{0}=3 \mathrm{~min}\right)$ & $\mathrm{CV}(\%)\left(h_{\text {inf }}, F_{0}=5 \mathrm{~min}\right)$ & $\mathrm{CV}(\%)\left(h_{\text {fin }}, F_{0}=5 \mathrm{~min}\right)$ \\
\hline 100 & 0.0 & 0.0 & 0.0 & 0.0 \\
105 & 0.0 & 0.0 & 0.0 & 0.0 \\
110 & 1.7 & 1.7 & 0.0 & 0.0 \\
115 & 5.5 & 4.5 & 2.5 & 2.6 \\
120 & 8.4 & 6.7 & 5.6 & 5.1 \\
125 & 11.1 & 8.8 & 8.2 & 6.8 \\
130 & 13.3 & 10.8 & 10.8 & 8.8 \\
135 & 14.6 & 11.9 & 11.5 & 9.7 \\
140 & 15.7 & 13.2 & 12.2 & 10.8 \\
145 & 15.9 & 14.9 & 13.3 & 11.2 \\
150 & 15.1 & 14.5 & 12.8 & 11.6 \\
155 & 14.9 & 15.0 & 13.1 & 12.0 \\
160 & 14.4 & & & 12.4 \\
\hline
\end{tabular}



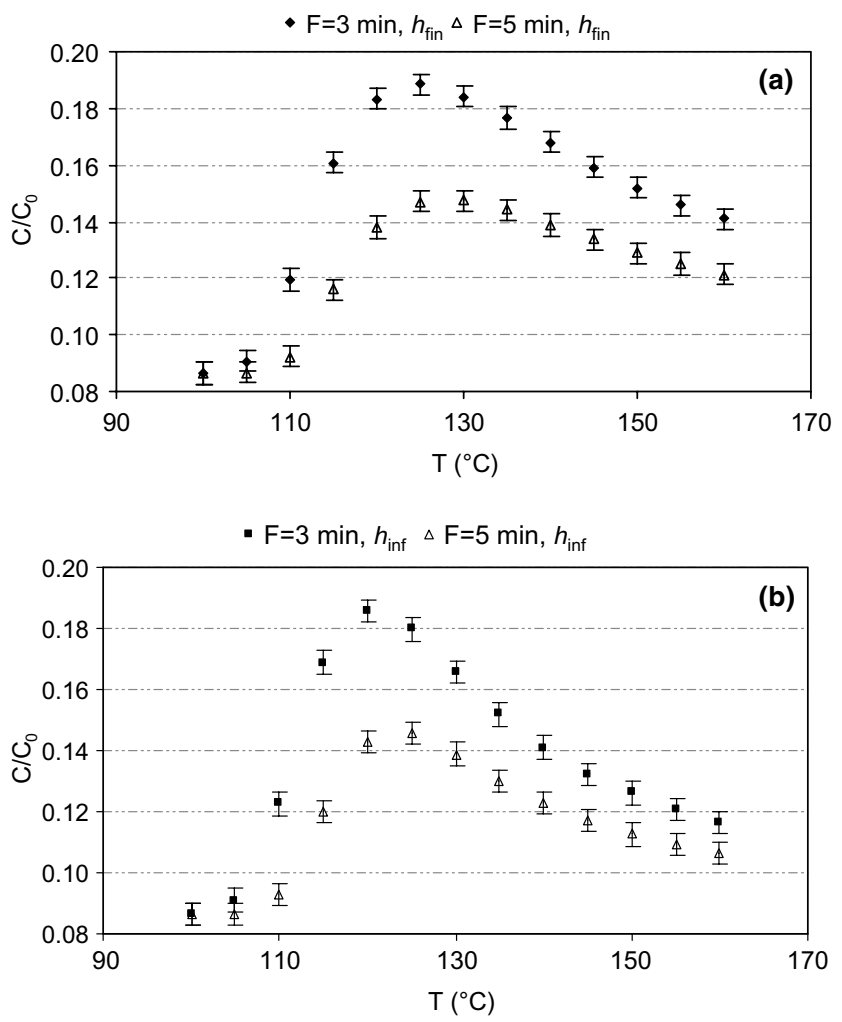

Fig. 2. Simulated non-uniformity in texture retention of white beans, for (a) finite and (b) infinite surface heat transfer coefficient, considering an $F_{0}$ value of 3 and 5 min and static retort mode of operation.

tures than the center and, consequently, a larger gradient in product quality retention can also be found.

An ANOVA was performed on all data for $0 \mathrm{rpm}$, showing significant main effects and their two-way and three-way interactions. Least significant differences between treatment means were subsequently computed at a 5\% significance level. Fig. 2 shows the optimum texture profile of the beans and LSDs, for finite (a) and infinite (b) surface heat transfer coefficients, and $F_{0}$ values of 3 and $5 \mathrm{~min}$. In this case, the LSD found (see Eq. (1)) was 0.0037 , which affects mainly the optimum range of quality retention. Observing Fig. 2 for a finite $h$ value (a) and an $F_{0}$ value of 3 min there are no significant differences between temperatures of 120 and $135^{\circ} \mathrm{C}$, which means that if the product is processed at any of these temperatures, its final average quality in terms of texture will be similar. For an $F_{0}$ value of $5 \mathrm{~min}$, no significant differences were found in the average texture of the beans processed above $120^{\circ} \mathrm{C}$. Comparing both $F_{0}$ values, all retentions are lower for an $F_{0}$ value of $5 \mathrm{~min}$ and the $\mathrm{CV}$ 's found were also lower (Table 2 and Fig. 2). To obtain a larger target $F_{0}$ value, for the same holding temperature, it is necessary to process the product for longer times and, consequently, the quality retention will be lower at the end.

When an infinite surface heat transfer coefficient is considered in the calculations, a similar optimum temperature range for both $F_{0}$ values can be observed (Fig. 2(b)). For an $F_{0}$ value of $3 \mathrm{~min}$, the optimum process temperature is between 120 and $125^{\circ} \mathrm{C}$, while for an $F_{0}$ value of $5 \mathrm{~min}$ between 120 and $130^{\circ} \mathrm{C}$.

The same reasoning can be made considering the rotation mode of operation $(10 \mathrm{rpm})$. The results of uncertainties of the combined effect of $C_{0}$ and adj. $f_{\mathrm{h}}$ on the final texture retention of white beans are shown in Table 3. A larger variability was found, as the CV values range from $0 \%$ to $15.7 \%$, considering also the experimental range of temperatures for retorts. However, despite this larger variability observed, the thermal process of white beans can still be optimized and optimum temperature ranges found were exactly the same (see Fig. 3(a) and (b) for a finite and infinite surface heat transfer coefficient, respectively). In this case, the LSD (see Eq. (1)) calculated was 0.0043 . Considering a finite $h$, for an $F_{0}$ value of $3 \mathrm{~min}$, no significant differences were found on quality retention for the temperature range of $120-135^{\circ} \mathrm{C}$. For an $F_{0}$ value of $5 \mathrm{~min}$, no significant differences were found for a process temperature above $120^{\circ} \mathrm{C}$. Considering an infinite surface heat

Table 3

Coefficients of variation $(\mathrm{CV})$ for simulated hardness retention of white beans at different holding temperatures, $F_{0}$ values of 3 and 5 min, finite and infinite surface heat transfer coefficients $(h)$ and rotation $(10 \mathrm{rpm})$ retort mode of operation

\begin{tabular}{lllll}
\hline$T\left({ }^{\circ} \mathrm{C}\right)$ & $\mathrm{CV}(\%)\left(h_{\text {inf }}, F_{0}=3 \mathrm{~min}\right)$ & $\mathrm{CV}(\%)\left(h_{\text {fin }}, F_{0}=3 \mathrm{~min}\right)$ & $\mathrm{CV}(\%)\left(h_{\mathrm{inf}}, F_{0}=5 \mathrm{~min}\right)$ & $\mathrm{CV}(\%)\left(h_{\text {fin }}, F_{0}=5 \mathrm{~min}\right)$ \\
\hline 100 & 0.0 & 0.0 & 0.0 & 0.0 \\
105 & 0.0 & 0.0 & 0.0 & 0.0 \\
110 & 2.3 & 1.6 & 0.0 & 0.0 \\
115 & 4.8 & 4.5 & 3.1 & 2.4 \\
120 & 7.9 & 6.2 & 6.8 & 5.2 \\
125 & 11.0 & 8.2 & 10.1 & 9.7 \\
130 & 13.5 & 9.7 & 12.6 & 11.2 \\
135 & 15.7 & 11.4 & 15.1 & 12.4 \\
140 & 17.4 & 13.5 & 16.4 & 13.6 \\
145 & 18.2 & 14.4 & 17.8 & 14.1 \\
150 & 18.8 & 15.3 & 17.5 & 14.7 \\
155 & 19.1 & 16.0 & 17.3 & 15.3 \\
160 & 19.0 & &
\end{tabular}



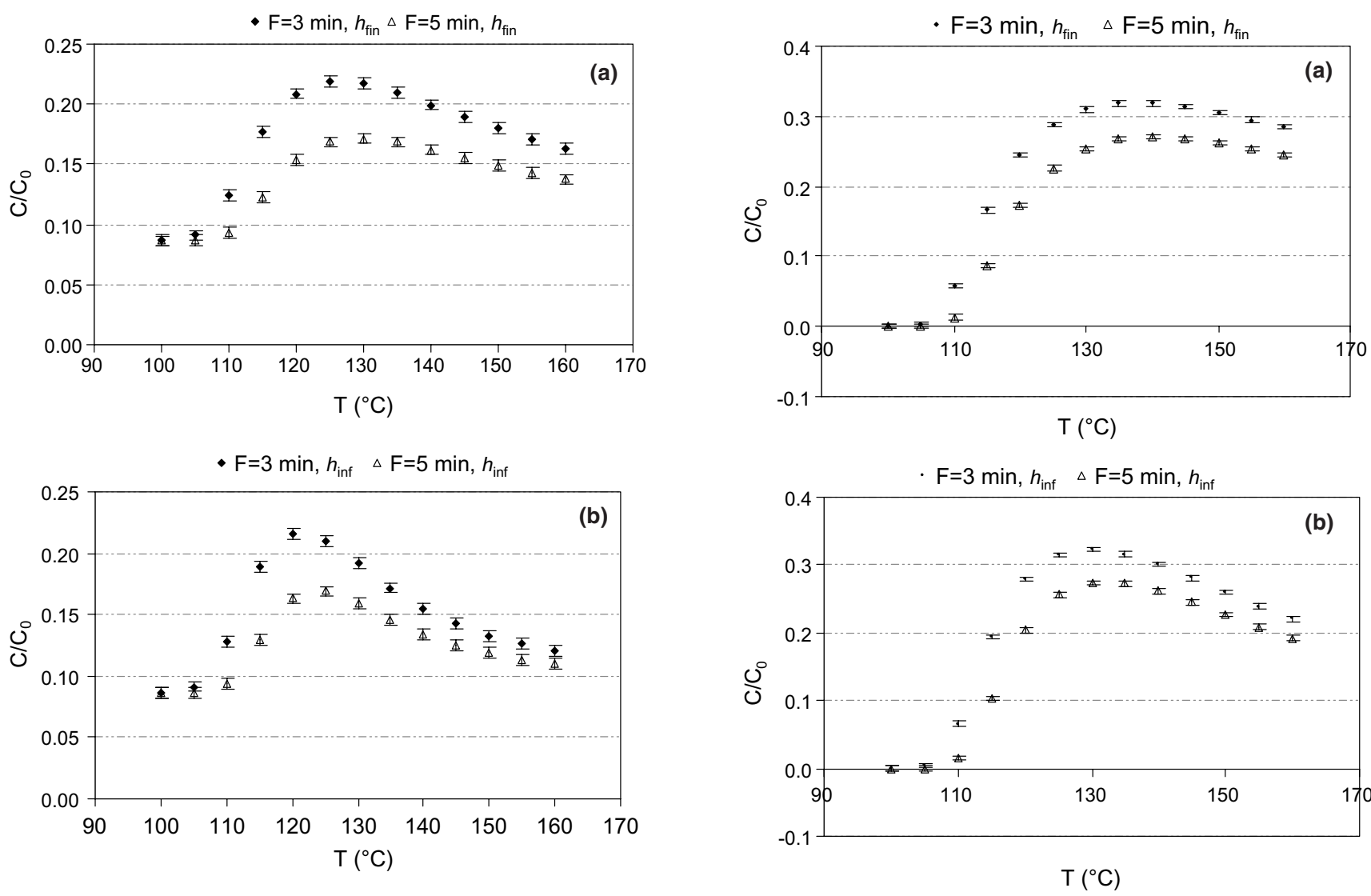

Fig. 3. Simulated non-uniformity in texture retention of white beans, for (a) finite and (b) infinite surface heat transfer coefficient and $F_{0}$ values of $3 \mathrm{~min}$ and $5 \mathrm{~min}$, considering rotation $(10 \mathrm{rpm})$ retort mode of operation.

Fig. 4. Simulated non-uniformity in color retention of green beans for (a) finite and (b) infinite surface heat transfer coefficient, considering $F_{0}$ values of 3 and $5 \mathrm{~min}$ and static retort mode of operation.

transfer coefficient and an $F_{0}$ value of $3 \mathrm{~min}$, the optimum temperature was between 120 and $125^{\circ} \mathrm{C}$, while for an $F_{0}$ value of $5 \mathrm{~min}$ between 120 and $130^{\circ} \mathrm{C}$. Therefore, for each $h$ value assumed, the optimum temperature range is the same for both static or rotary retort modes of operation. Another important observation is the lower quality retention found for the static retort mode of operation, when comparing with the rotary retort mode. For the rotary mode, the heat is transferred

much faster to the product, and consequently a lower time is needed to reach the same $F_{0}$ value. Therefore, the final product quality retention is increased.

\section{Green beans}

The simulated variability on color retention $(-a / b)$ of green beans is presented in Fig. 4, for (a) finite and (b) infinite surface heat transfer coefficients and $F_{0}$ values

Table 4

Coefficients of variation $(\mathrm{CV})$ for simulated color $(-a / b)$ retention of green beans at different holding temperatures, $F_{0}$ values of 3 and 5 min, finite and infinite surface heat transfer coefficients $(h)$ and static retort mode of operation

\begin{tabular}{lllll}
\hline$T\left({ }^{\circ} \mathrm{C}\right)$ & $\mathrm{CV}(\%)\left(h_{\mathrm{inf}}, F_{0}=3 \mathrm{~min}\right)$ & $\mathrm{CV}(\%)\left(h_{\mathrm{fin}}, F_{0}=3 \mathrm{~min}\right)$ & $\mathrm{CV}(\%)\left(h_{\mathrm{inf}}, F_{0}=5 \mathrm{~min}\right)$ & $\mathrm{CV}(\%)\left(h_{\mathrm{fin}}, F_{0}=5 \mathrm{~min}\right)$ \\
\hline 105 & 2.6 & 1.4 & 0.0 & 0.0 \\
110 & 1.7 & 1.7 & 2.0 & 1.7 \\
115 & 2.3 & 2.1 & 2.3 & 2.3 \\
120 & 2.8 & 2.5 & 3.1 & 3.8 \\
125 & 3.3 & 2.8 & 3.6 & 3.5 \\
130 & 3.8 & 3.0 & 4.2 & 3.7 \\
135 & 4.3 & 3.3 & 4.8 & 4.1 \\
140 & 5.0 & 3.6 & 5.5 & 4.5 \\
145 & 5.6 & 3.8 & 6.3 & 4.7 \\
150 & 6.4 & 4.2 & 7.1 & 5.1 \\
155 & 7.2 & 4.4 & 7.9 & 5.5 \\
160 & 7.9 & 4.7 & 8.7 &
\end{tabular}


of 3 and $5 \mathrm{~min}$. The overall $\mathrm{CV}$ values range from $0 \%$ to $4.8 \%$ (Table 4 ) considering again only the experimental operational retort temperatures, which means that the variability in the final color retention is lower than for the case of texture loss of white beans.

LSDs performed at a $5 \%$ significance level (value equal to 0.0033), show no significant differences for color retention in the temperature range $130-150{ }^{\circ} \mathrm{C}$, for an $F_{0}$ value of $3 \mathrm{~min}$ and finite $h$ value (Fig. 4a). For an $F_{0}$ value of $5 \mathrm{~min}$, no significant differences were found when using temperatures higher than $135^{\circ} \mathrm{C}$ (Fig. 4a). Therefore, for a finite $h$ value the optimum process temperature to give the maximum color retention for green beans is around 130 to $135^{\circ} \mathrm{C}$. These temperatures are also near the maximum limit permitted by an industrial retort. Considering an infinite $h$ value (Fig. 4b), no significant differences were found from 125 to $135^{\circ} \mathrm{C}$. At this range, maximum color retention for green beans was obtained considering an $F_{0}$ value of 3 or $5 \mathrm{~min}$. As was expected, lower color retentions were obtained for the $F_{0}$ value of $5 \mathrm{~min}$.

\section{Conclusions}

In the case studies presented, with green and white beans, optimum sterilization conditions in terms of final quality retention were found by simulation. Taking into account the statistical analysis performed, important conclusions can be taken about the possibility of process optimization. In the case of white beans, for static and rotation retort modes of operation, uncertainties in the heating rate index and initial hardness have large effects on the final average texture variability, at high temperatures. The optimum range of quality retention was mainly affected. However, it is still possible to obtain lower hardness losses for process temperatures between $120^{\circ} \mathrm{C}$ and $135^{\circ} \mathrm{C}$. In the case of green beans, the uncertainties in the heating rate index did not affect so largely the final color retention. The optimum process temperature ranged from 125 to $135^{\circ} \mathrm{C}$. Therefore, it is possible to design the optimum process for both case studies. This means that, particularly for these case studies, if the product is processed at the temperatures pointed out previously, maximum hardness values for white beans and color retentions of green beans will be experimentally obtained. However, the process temperature should be chosen taking into account the $F_{0}$ value and the material used to pack the product (glass or metal), as this influences the surface heat transfer coefficient value.

Therefore, the approach applied is a valuable tool to get an idea of the non-uniformity in process quality retention. Consequently, the existence of an optimum process, in terms of maximizing quality, is possible to be assessed. With this knowledge, decisions can be taken, whether to reduce quality degradation and costs or, if it is not possible at all to optimize quality retention, to minimize only costs.

As in any simulation study, the objective is to try to mimic reality as much as possible, but unfortunately some assumptions had to be made. In the present study the assumptions performed in the calculations should be kept in mind: variations in initial hardness value of white beans were assumed to be normally distributed; the finite differences model used to calculate quality retentions, although already proved to be a reliable program (Ávila et al., 1999), was developed for homogeneous and conduction heating foods; other sources of uncertainties could have been taken into account (see Section 1). An important aspect, in designing a process, is to combine all the possible sources of uncertainty to get the correct idea of the overall effects on the final quality variability.

\section{Acknowledgment}

Isabel M.L.B. Ávila acknowledges the Fundação para a Ciência e a Tecnologia grant (PRAXIS XXI/ $\mathrm{BD} / 13502 / 97)$, that allowed this research work to be carried out at Escola Superior de Biotecnologia, Universidade Católica Portuguesa, Portugal.

\section{References}

Ávila, I. M. L. B. (2001). Experimental validation of optimal sterilisation conditions for maximising volume average quality retention of prepackaged foods. Escola Superior de Biotecnologia, Universidade Católica Portuguesa, Porto.

Ávila, I. M. L. B., Smout, C., Silva, C. L. M., \& Hendrickx, M. (1999). Development of a novel methodology to validate optimal sterilisation conditions for maximising texture quality of white beans in glass jars. Biotechnology Progress, 15, 565-572.

Ball, C. O. (1923). Thermal process time for canned foods. Bull. 37; National Research Council: Washington, DC.

Banga, J. R., Balsa-Canto, E., Moles, C. G., \& Alonso, A. A. (2003). Improving food processing using modern optimisation methods. Trends in Food Science and Technology, 14(4), 131-144.

Clealand, A. C., \& Robertson, G. L. (1985). Determination of thermal processes to ensure commercial sterility of food in cans. In S. Thorne (Ed.). Developments in food preservation (Vol. 3, pp. 1). London: Elsevier Applied Science Publishers.

Hahn, G. J., \& Shapiro, S. S. (1994). Statistical Models in Engineering. New York: John Wiley \& Sons.

Hayakawa, K., De Massaguer, P., \& Trout, R. J. (1988). Statistical variability of thermal process lethality in conduction heating foodcomputerised simulation. Journal of Food Science, 53(6), 1887-1893.

Hayakawa, K., \& Timbers, G. E. (1977). Influence of heat treatment on the quality of vegetables: changes in visual green colour. Journal of Food Science, 42(3), 778-781.

Herndon, D. H. (1971). Population distribution of heat rise curves as a significant variable in heat sterilisation process calculations. Journal of Food Science, 36, 299-305.

Hicks, E. W. (1961). Uncertainties in canning process calculations. Journal of Food Science, 26, 218-226. 
Jones, A. T., Pflug, I. J., \& Blanchett, R. (1980). Effect of fill weight on the $F$-value delivered to two styles of green beans processed in a sterilmatic retort. Journal of Food Science, 45, 217-220.

Lenz, M. K., \& Lund, D. B. (1977). The lethality-Fourier number method: confidence intervals for calculated lethality and mass average retention of conduction-heating canned foods. Journal of Food Science, 42(4), 1002-1007.

Levenspiel, O. (1999). Kinetics of homogeneous reactions. In Chemical reaction engineering (3rd ed., pp. 13-32). New York: John Wiley \& Sons.

Lund, D. B. (1975). Effects of blanching, pasteurisation and sterilisation on nutrients. In R. S. Harris \& E. Karmas (Eds.), Nutritional evaluation of food processing (pp. 205). Westport, CT, New York: AVI Publishing CT.

Lund, D. B. (1978). Statistical analysis of thermal process calculations. Food Technology, 32(3), 76-78.

Neter, J., Kutner, M. H., Nachtsheim, C. J., \& Wasserman, W. (1996). Applied Linear Statistical Models. Chicago, USA: Irwin.

Nicolai, B. (1994). Modelling and uncertainty propagation analysis of thermal food processes. Ph.D. thesis. Belgium: Katholieke Universiteit Leuven.

Noronha, J., Hendrickx, M., Van Loey, A., \& Tobback, P. (1995). New semi-empirical approach to handle time-variable boundary conditions during sterilisation of non-conductive heating foods. Journal of Food Engineering, 24, 249-268.

Patino, H., \& Heil, J. R. (1985). A statistical approach to error analysis in thermal process calculations. Journal of Food Science, 50, $1110-1114$.
Powers, J. J., Pratt, D. E., Carmon, J. L., Somaatmadja, D., \& Fortson, J. C. (1962). Application of extreme-value methods and other statistical procedures to heat penetration data. Food Technology, 16(3), 80-89.

Robertson, G. L., \& Miller, S. L. (1984). Uncertainties associated with the estimation of $F_{0}$ values in cans, which heat by conduction. Journal of Food Technology, 19, 623-630.

Smout, C. (1999). Heat distribution and heat penetration trials as a basis for evaluating non-uniformity of lethality in batch overpressure retort processing. Ph.D. thesis. Belgium: Katholieke Universiteit Leuven.

Smout, C., Ávila, I. M. L. B., Van Loey, A. M. L., Hendrickx, M., \& Silva, C. L. M. (2000a). Influence of rotational speed on the statistical variability of heat penetration parameters and on the non-uniformity of lethality in retort processing. Journal of Food Engineering, 45(2), 93-102.

Smout, C., Van Loey, A. M. L., \& Hendrickx, M. E. G. (2000b). Nonuniformity of lethality in retort processes based on heat distribution and heat penetration data. Journal of Food Engineering, 45, 103-110.

Smout, C., Banadda, N. E., Van Loey, A. M. L., \& Hendrickx, M. E. G. (2003). Non-uniformity in lethality and quality in thermal process optimization: a case study on color degradation of green peas. Journal of Food Science, 68(2), 545-550.

Statistica Inc. (2001). Statistica Software: Release 6.0, Oklahoma, USA.

Varga, S. (1998). A new approach model and assess process variability in batch retorts. Ph.D. thesis. Escola Superior de Biotecnologia, Porto, Portugal. 